http://jmscr.igmpublication.org/home/ ISSN (e)-2347-176x ISSN (p) 2455-0450 crossref DOI: https://dx.doi.org/10.18535/jmscr/v8i1.75

\title{
Nutritional assessment of early adolescents: Cross sectional study from largest tertiary care centre of Gujarat
}

Authors

\section{Sandeep Jhajra Dayanand ${ }^{1}$, Meera Pillai ${ }^{2}$, Arpita Dash ${ }^{3 *}$, Debasish Nanda ${ }^{4}$,} Kavitha Mallesh ${ }^{5}$, Shivani Deshwal ${ }^{6}$, Srishti Goel ${ }^{7}$, Bela H Shah ${ }^{8}$

${ }^{1}$ Department of Neonatology, Postgraduate Institute of Medical Sciences, Rohtak

${ }^{2}$ Department of Anaesthesia, Postgraduate Institute of Medical Sciences, Rohtak

${ }^{3}$ Department of Medicine, IMS and SUM hospital, Siksha “O” Anusandhan University (Deemed to be), K8,

Kalinganagar, Bhubaneswar-751003, Odisha, India

${ }^{4}$ Department of Neonatology, IMS and SUM hospital, Siksha “O” Anusandhan University (Deemed to be),

K8, Kalinga Nagar, Bhubaneswar-751003, Odisha, India

${ }^{5}$ Resident, Department of Paediatrics, Postgraduate Institute of Medical Sciences, Rohtak

${ }^{6}$ Resident, Department of Psychiatry, Postgraduate Institute of Medical Sciences, Rohtak

${ }^{7}$ Assistant professor, Department of Neonatology, Lady Hardinge Medical College, New Delhi

${ }^{8}$ Professor, Department of Pediatrics, B J Medical College, Ahmedabad, Gujarat

\section{*Corresponding Author}

\section{Arpita Dash}

Department of Medicine, IMS and SUM hospital, Siksha "O" Anusandhan University (Deemed to be), K8, Kalinganagar, Bhubaneswar-751003, Odisha, India

\footnotetext{
Abstract

Background: Adolescence is a complex phase of physical, sexual and psychological development. Despite having various health programmes directed towards adolescent health like Kishori Shakti Yojana, Rashtriya Kishor Swasthya Karyakram etc, the prevalence of malnutrition remains high. Large population, poor condition of health infrastructure, large socioeconomic disparity, lack of basic health care facilty in remote areas, lack of accessibility to health care facility in many areas are some of the reasons for this high prevalence.

Methods: This was a hospital based prospective observational study, conducted in one of the largest tertiary care centre of India, over a period of 18 months. Patients in the early adolescent age group of 10-14 years who required admission to the hospital were included and body mass index (BMI) for age was used for classifying the nutritional status in terms of thinness (BMI for age below 5th percentile), normal (BMI for age between 5th to 85th percentile) and overweight (BMI for age $>85$ th percentile).

Results: The study group comprised of 190 early adolescent (114 boys and 76 girls). Overall prevalence of malnutrition, thinness and underweight was $66.3 \%, 56.8 \%$ and $9.5 \%$ respectively. Girls were affected more as compared to boys. Malnutrition was more common in lower socioeconomic class and those whose mothers were either illiterate or had primary level of education Two -third girls (63\%) and around half of boys were anaemic. Deficiency of vitamin A, Vitamin B and Vitamin C was found in $7.3 \%, 8.9 \%$ and $0.1 \%$ respectively. .and dental Caries, Refractive errors and skin problems occurred in $17.89 \%, 5.26 \%$ and $9.4 \%$ children

Conclusion: Health and nutrition related issues are highly prevalent among adolescent age group in India. Policy makers should make an attempt to bridge the gaps in our health system and various health programmes for adolescents and plan strategic interventions to overcome problem of malnutrition.

Keywords: Adolescent; Thinness; Overweight; Anaemia.
} 


\section{Introduction}

The adolescent period is a transition period between childhood and adulthood between 10 to 19 years of age characterized by physical, psychological, and hormonal changes. ${ }^{1}$ Around $20 \%$ of Indian population belongs to adolescent age group which provides a huge workforce in the future. ${ }^{2}$ Despite having adolescent friendly health clinics and various health programmes targeting adolescents, malnutrition is one of the major public health problem in India, similar to other south east Asian countries. A huge population burden of 137 million, poor condition of health infrastructure and a large socioeconomic disparity are the main reasons for various health related problems in adolescent population. In this era of electronic revolution, television and internet exposure are one of the deciding factors of various food habits and lifestyle behaviours of adolescents. Unbalanced diet and sedentary life style during the adolescent phase is the root cause of many of the adult onset diseases. Mental disorders like eating problems, depression etc are on the rise in our adolescent population.

In this era of electronic revolution, $\mathrm{TV}$ and internet ads are one of the deciding factors of various food habits and lifestyle behaviours of our children.

Anthropometric indicators are useful both at an individual and population level. At an individual level, anthropometric indicators can be used to assess compromised health or nutrition wellbeing. This information can be valuable for screening children for interventions and for assessing the response to interventions. At the population level, anthropometry can be used to assess the nutrition status within a country, region, community, or socioeconomic group, and to study both the determinants and consequences of malnutrition. This form of monitoring is valuable both for the design and targeting of health and nutrition interventions.

Anthropometric parameters like weight, height, BMI for age can be used as a screening tool at individual level and at community level to quantify the problem of malnutrition in adolescent population. ${ }^{3} \mathrm{~A}$ central database for documenting adolescent health problems might be of help which can be used by our policymakers to develop suitable health programmes to combat this menace of malnutrition and prevent long term complication.

\section{Methodology}

Children between age group of $10-14$ years of age who were admitted to $\mathrm{C} 2$ pediatric ward at $\mathrm{B} \mathrm{J}$ Medical college civil hospital Ahmedabad, Gujarat were included in the study. Those who were critically ill moribund, had anaemia due to non- nutritional causes (sickle cell anaemia, thalassemia) were excluded School records/birth certificate were used to ascertain age of the adolescents.

\section{Anthropometric measurements}

Height: Children were asked to stand barefoot on a flat surface against a wall with feet together and look straight. A stadiometer with a sliding head piece was used to measure height to the nearest $0.1 \mathrm{~cm}$.

Weight: Electronic weighing scale on a flat and firm surface was used to measure body weight. Weighing scale was scanned regularly for zero error and calibrated against known weight periodically.

According to World Health Organisation (WHO), BMI for age criteria was used as a screening tool to classify nutritional status in enrolled candidates $^{4}$ as thinness (BMI for age $<5^{\text {th }}$ percentile), and overweight (BMI for age $>85^{\text {th }}$ percentile). Modified Kuppuswamy scale was used to classify socioeconomic status. General examination was done in all adolescents to assess for anaemia, vitamin deficiencies, skin problems (scabies, pyoderma) and laboratory test were used to diagnose and categorize anaemia as mild, moderate and severe anaemia as per WHO standards. Bad breath, bleeding gums, teeth caries were considered a marker of poor oral hygiene.

Tanners sexual Maturity Rating Scale was used to assess Sexual development and ophthalmic 
evaluation was done by ophthalmologist to look for common errors of refraction. ${ }^{5}$ Institute ethical committee approval was obtained. Data was collected and analysed using SPSS (Statistical Packages for the Social Sciences) version 10 software.

\section{Results}

A total of 7960 patients were admitted in paediatric department over a period of 18 months, of which $854(10.7 \%)$ patients were between the age group of 10-14 years. A total of 220 adolescent patients were admitted in $\mathrm{C} 2$ Ward of the hospital. After consideration of inclusion and exclusion criteria, the final study group included $190(2.38 \%)$ early adolescent patients with male predominance $(60 \%)$. These patients were admitted for various medical problems and were included in the study only when cured of the primary illness.

Overall, 126(66.3\%) adolescents were suffering from some form of malnutrition. About $56.8 \%$ of the adolescents were thin; $33.6 \%$ were normal and $9.5 \%$ were overweight (Table 1). The mean BMI was higher among boys $(14.8 \pm 4.2)$ as compared to girls' $(14.14 \pm 4.1)$. Similarly, the prevalence of malnutrition was significantly higher in girls $(72.3 \% \mathrm{v} / \mathrm{s} 62.3 \%)$, lower socio-economic class, those living in joint family (81\% v/s 58\%) and whose mother were uneducated or having primary level of education (Table 2).

Two-third (55.7\%) had nutritional anaemia with mild, moderate and severe anaemia present in $55.2 \%, 37.9 \%$ and $6.2 \%$ respectively. Among girls, overall the prevalence of nutritional anaemia was higher $(63.15 \%)$ as compared to boys with $45.8 \%$ and $10.4 \%$ having moderate and severe anaemia respectively. Other nutritional deficiencies observed were vitamin A deficiency (7.3\%), Vitamin B deficiency $(8.9 \%)$ and other vitamin deficiencies (17.8\%). Around one fifth $(18 \%)$ had tooth caries and $10 \%$ had some skin problems in the form of scabies, acnevulgaris, eczema and seborrheic dermatitis. Nearly $10 \%$ of the total study population had indulged in some form of substance abuse with pan, gutkha and alcohol (Table 3 \& 4)

Among males, three - fourths $(76.3 \%)$ were in SMR Stage I with rest in SMR Stage II and among females, $53.9 \%$ were in SMR stage I, $30.3 \%$ in SMR stage II and $15.8 \%$ in SMR stage III (Table 5).

Table 1: Prevalence of malnutrition as per BMI for age

\begin{tabular}{|l|l|c|c|c|c|}
\hline Variables & & & Thinness & Normal & Overweight \\
\hline \multirow{3}{*}{ Sex } & Male & $114(60 \%)$ & 60 & 43 & 11 \\
\cline { 2 - 6 } & Female & $76(40 \%)$ & 48 & 21 & 7 \\
\cline { 2 - 6 } & Total & $190(100 \%)$ & $108(56.8 \%)$ & $64(33.7 \%)$ & $18(9.5 \%)$ \\
\hline
\end{tabular}

Table 2: Demographic variables

\begin{tabular}{|l|c|c|c|c|}
\hline Variable & & $\begin{array}{c}\text { Presence of } \\
\text { malnutrition }\end{array}$ & $\begin{array}{c}\text { Absence of } \\
\text { malnutrition }\end{array}$ & $\begin{array}{c}\text { Total } \\
(\mathbf{N = 1 9 0})\end{array}$ \\
\hline \multirow{4}{*}{ Type of Family } & Nuclear & $71(58.2 \%)$ & $51(41.8 \%)$ & 122 \\
\cline { 2 - 5 } & Joint & $55(80.8 \%)$ & $13(19.2 \%)$ & 68 \\
\cline { 2 - 5 } $\begin{array}{l}\text { Socioeconomic } \\
\text { status }\end{array}$ & Total & 126 & 64 & $190(100 \%)$ \\
\cline { 2 - 5 } & Lower & $70(55.5 \%)$ & $28(43.8 \%)$ & 98 \\
\cline { 2 - 5 } & Upper lower & $40(31.7 \%)$ & $25(39.1 \%)$ & 65 \\
\cline { 2 - 5 } & Lower middle & $15(11.9 \%)$ & $7(10.9 \%)$ & 22 \\
\cline { 2 - 5 } & Upper middle & $1(0.8 \%)$ & $4(6.2 \%)$ & 5 \\
\cline { 2 - 5 } & Upper & 0 & 0 & 0 \\
\cline { 2 - 5 } & Total & 126 & 64 & 71 \\
\cline { 2 - 5 } & Illiterate & $67(53.1 \%)$ & $4(6.2 \%)$ & 64 \\
\cline { 2 - 5 } & Primary school & $46(36.5 \%)$ & $18(28.1 \%)$ & 39 \\
\cline { 2 - 5 } & Middle school & $12(9.5 \%)$ & $27(42.2 \%)$ & 12 \\
\cline { 2 - 5 } & High school & $1(0.8 \%)$ & $11(17.2 \%)$ & 4 \\
\cline { 2 - 5 } & Graduate & 0 & $4(6.2 \%)$ & $190(100 \%)$ \\
\cline { 2 - 5 } & Total & 126 & 64 & $7100 \%)$ \\
\hline
\end{tabular}


Table 3: Gender wise morbidities in adolescents

\begin{tabular}{|l|c|c|c|}
\hline Common problems & $\begin{array}{c}\text { Male } \\
\mathbf{N = 1 1 4}\end{array}$ & $\begin{array}{c}\text { Female } \\
\mathbf{N = 7 6}\end{array}$ & $\begin{array}{c}\text { Total } \\
\mathbf{N = 1 9 0}\end{array}$ \\
\hline Anaemia & $58(50.8 \%)$ & $48(63.2 \%)$ & $106(55.8 \%)$ \\
\hline Vit A deficiency & $6(5 \%)$ & $8(10.5 \%)$ & $14(7.3 \%)$ \\
\hline Vit B deficiency & $7(6.1 \%)$ & $10(13.2 \%)$ & $17(8.9 \%)$ \\
\hline Vit C deficiency & $1(0.8 \%)$ & 0 & $1(0.1 \%)$ \\
\hline Tooth Caries & $15(13.2 \%)$ & $19(25 \%)$ & $34(17.8 \%)$ \\
\hline Skin problems & 11 & 7 & $18(9.4 \%)$ \\
\hline Worms infestation & 5 & 3 & $8(4.2 \%)$ \\
\hline Refractive errors & 4 & 6 & $10.5 .3 \%)$ \\
\hline Substance abuse & 19 & 1 & $20(10.5 \%)$ \\
\hline
\end{tabular}

Table 4: Grading of anaemia in early adolescents

\begin{tabular}{|l|c|c|c|}
\hline Grading & Male & Female & Total \\
\hline Mild & $32(55.2 \%)$ & $21(43.75 \%)$ & 53 \\
\hline Moderate & $22(37.9 \%)$ & $22(45.8 \%)$ & 44 \\
\hline Severe & $4(6.2 \%)$ & $5(10.4 \%)$ & 9 \\
\hline Total & $58(100 \%)$ & $48(100 \%)$ & 106 \\
\hline
\end{tabular}

Table 5: SMR Staging in Adolescents

\begin{tabular}{|l|c|c|c|}
\hline SMR Stage & Male & Female & Total \\
\hline Stage - I & $87(76.3 \%)$ & $41(53.9 \%)$ & $128(67.3 \%)$ \\
\hline Stage - II & $27(23.7 \%)$ & $23(30.3 \%)$ & $50(26.3 \%)$ \\
\hline Stage - III & - & $12(15.9 \%)$ & $12(6.3 \%)$ \\
\hline Stage - IV & - & - & - \\
\hline Stage - V & - & - & - \\
\hline Total & $\mathbf{1 1 4}$ & $\mathbf{7 6}$ & $\mathbf{1 9 0}(\mathbf{1 0 0 \% )}$ \\
\hline
\end{tabular}

\section{Discussion}

This study, conducted from one of the largest centre in south East Asia, identifies the extent of malnutrition prevalent among the early adolescent age group. This is one of the first studies that primarily focused on the early adolescent age group. In the present study, $56.8 \%$ of the adolescents were thin, $9.5 \%$ were overweight while $33.7 \%$ were normal with prevalence being higher in girls. The results are comparable to other studies from developing countries. Deshmukh et $\mathrm{al}^{6}$ reported $53.8 \%$ thinness and $2.2 \%$ overweight problem in adolescents while Shahabuddin et $\mathrm{al}^{7}$ reported $67.0 \%$ prevalence of thinness in Bangladesh.

In this study, the prevalence of thinness was found to be higher in girls $(63.2 \%)$ than boys $(52.6 \%)$. Deshmukh et $\mathrm{al}^{6}$ also reported higher prevalence of thinness in girls than boys. In a study by Singh et $\mathrm{al}^{8}$, prevalence of thinning among boys was $46.7 \%$ and among girls was $53.3 \%$ respectively. A study byde Onis et $\mathrm{al}^{9}$ reported prevalence of thinness to be more among boys $50.5 \%$.
It was observed that the incidence and extent of malnutrition was inversely proportional to the education level of the mothers. Malnourishment was more prevalent in adolescents belonging to lower socioeconomic class $(55.5 \%)$ as compared to upper lower socioeconomic class (31.7\%). Hesketh et $\mathrm{al}^{10}$ also reported that low household income is a direct predictor of nutrition related problems. National Nutrition Monitoring Bureaudata reported that there is a wide gap between growth rates of adolescents belonging to lower socioeconomic class as compared to those belonging to higher income groups. ${ }^{11}$

Nearly three fifth of the study population was suffering from nutritional anaemia, adolescent girls being affected more than boys. This is similar to the studies conducted by Bhattacharya et $\mathrm{al}^{12}$ and Ananthakrishnan et $\mathrm{al}^{13}$ who have documented the prevalence of anaemia in adolescent age group to be $55.18 \%$ and $57.2 \%$ respectively in their studies.

Besides a high incidence of nutritional anaemia, other nutrient deficiencies (vitamin A\&B), dental caries and skin problem were found to be common 
in adolescents. The findings are similar to studies from other parts of country and those from developing nations. Dambhare et $\mathrm{al}^{14}$ showed prevalence of Vitamin A deficiency and vitamin B complex deficiency to be around $0.86 \%$ and $14.66 \%$ respectively among adolescents at Wardha. Bhattacharya et $\mathrm{al}^{12}$ found the prevalence of Vitamin A deficiency to be $8.01 \%$ and prevalence of Vitamin B deficiency was $27.6 \%$. In study by Ananthakrishnan ${ }^{13} 3.1 \%$ of adolescents were deficient in vitamin A and $32.9 \%$ were suffering from riboflavin deficiency. Bashar et $\mathrm{al}^{15}$, found similar level of vitamin A deficiency in their study.

Prevalence of tooth caries and refractive error was $17.8 \%$ and $5.3 \%$ respectively in the current study. The prevalence of caries tooth and refractive errors was documented to be $35.34 \%$ and $13.8 \%$ respectively in study by Dambhare et al ${ }^{14}$, while it was $40.33 \%$ and $33.5 \%$ respectively in study by Bhattacharya et $\mathrm{al}^{12}$. Modi et $\mathrm{al}^{16}$ reported an incidence of around $22.6 \%$ and $8.8 \%$ respectively. Similarly Bashar et $\mathrm{al}^{15}$ have documented an incidence of $18.3 \%$ and $26.8 \%$ respectively.

Prevalence of skin problems like scabies and worm infestation was $9.4 \%$ and $4.2 \%$ respectively in current study. The prevalence of skin problem and refractive errors was $6.8 \%$ and $7.7 \%$ respectively as documented by Dambhare et $\mathrm{al}^{14}$. Around $38.8 \%$ and $23.1 \%$ of adolescents had documented to have scabies and worm infestation by Bhattacharya et $\mathrm{al}^{12}$, while it was $11.1 \%$ and $9.7 \%$ respectively in study by Bashar et $\mathrm{al}^{15}$.

In present study maximum number of male and female patients were in SMR Stage I and SMR stage II. Agarwal et $\mathrm{al}^{17}$ and kaul et al ${ }^{18}$ study showed that most of early adolescents were in SMR stage I and stage II.

Specific finding coming out of this study is that malnutrition and other nutrition related morbidities are very common among adolescent population. Despite having various programmes directed towards adolescent health prevalence of malnutrition is still very high. A large population size, socioeconomic disparity, poor access to health facilities and illiteracy are mainly responsible for malnutrition among adolescent. Severity of malnutrition during adolescent phase is likely to impact the health later in life in form of various noncommunicable diseases like diabetes mellitus, hypertension and psychological problems like anorexia nervosa, depression etc. Adolescent population and its nutrition should be the priority of our policymakers formulating various health programmes of our country. There is a need for having specific national policies for reaching this vulnerable population in different settings like in rural areas, urban slums, schools etc. The problem related to gender discrimination needs to be addressed. There is also an urgent need to address socioeconomic factors and lifestyle changes to overcome this menace of malnutrition in our adolescent population.

Secondly anthropometric assessment is used to quantify the problem of malnutrition at the community level. Conventional indices like height for age or weight for age or weight for height which are commonly being used in various studies are likely to give improper findings and biased results. Therefore BMI for age should be used as a screening tool to assess quantum of thinness and overweight in adolescent population. WHO recommends using BMI for age as a screening tool to classify impact of malnutrition, because it is consistent with adult indicators and it was also found have a correlation with clinical risk factors of various non communicable diseases like hypertension and it is significantly correlated with total body fat. ${ }^{3}$

\section{Conclusion}

Even in $21^{\text {st }}$ century with an economy of 3 trillion we are still dealing with problem of malnutrition in our adolescent population. Problems of prematurity, In trauterine growth retardation etc are all related to menace of malnutrition and anaemia in adolescent girl population. Special focus on micronutrient deficiency along with proper nutrition is instrumental in breaking the vicious cycle of undernutrition and diseases. It 
must be realised that investing in the nutrition of adolescent would help the nation in the long term. A central database for documenting adolescent health related issues might help to guide health stakeholders to formulate adequate guidelines to tackle the serious problem of malnutrition in our country.

\section{Funding: None}

Conflict of interest: None.

Ethical Disclosure: Institute ethical committee approval was taken prior to this study and written informed consent in local language was taken from legal guardians of the study participants.

\section{References}

1. World Health Organization. Adolescent Health at a glance in South East Asia Region 2007. Factsheet. New Delhi: WHO Regional Office for South East Asia, Adolescent Health and Development Unit: 2007

2. UNFPA (United Nations Population Fund) for UN system in India. Section One: Situational Analysis of Adolescents in India. Adolescents in India: A profile 2011.

3. World Health Organization. Physical status: use and interpretation of anthropometry. In: WHO, eds. WHO Technical Report Series No. 854. Geneva: World Health Organization; 1995: 1-439.

4. WHO Multicentre Growth Reference Study Group. WHO Child Growth Standards: Length/height-for-age, weightfor-age, weight-forlength,weight-forheight and body mass index-for-age: methods and evelopment. Geneva: World Health Organization, 2006.

5. Tanner JM. Fetus into man. In: Tanner JM, eds. Physical Growth from Conception to Maturity. 1st ed. New York, Wells: Open Book Publishing Limited; 1978: 22-36.

6. Deshmukh PR, Gupta SS, Bharambe SS, Dongre AR, Maliye $\mathrm{C}$ et al. Nutritional status of adolescents in rural Wardha. Indian J Pediatr 2006;73:139-141.

7. Shahabuddin AK, Talukdar I4,Talukdar MK, Hassan M, Seal A et al. Adolescent nutrition in a rural community in Bangladesh. Indian] Pediatr 2000 Feb; 67(2): 93-98.

8. Singh JP, Kariwal P, Gupta SB, Singh A $\mathrm{K}$, Imtiaz D. Assessment of nutritional status among adolescents: a hospital based cross sectional study.Int J Res Med Sci. 2014 May;2(2):620-624.

9. De Onis M, Dasgupta P, Saha S, Sengupta D, Blossner M. The National Centre for Health Statistics reference and the growth of Indian adolescent boys. Am j Clin Nutr 2001 Aug; 74(2): 248- 253.

10. Hesketh T, Ding QJ, Tomkins AM. Disparities in economic development in Eastern China: impact on nutritional status of adolescents. Public Health Nutr2002 Apr; 5(2): 313-318.

11. Kanani S, Consul P. Nutrition health profile and intervention strategies for underprivileged adolescent girls in India: aselected review. Indian j Matern Child Health 1990 Oct-Dec; 1(41: 129-133.

12. Bhattacharya A, Basu M, Chatterjee S, Misra RN, Chowdhury G. Nutritional status and morbidity profile of schoolgoing adolescents in a district of West Bengal. Muller J Medical Sciences \& Research 2015.6:10-15.

13. Ananthakrishnan S, Pani SP, Nalini P. A comprehensive study of morbidity in school age children. Indian Pediatr 2001;38.

14. Dambhare DG, Bharambe MS, Mehendale AM, Garg BS. Nutritional Status and Morbidity among School going Adolescents in Wardha, a Peri-Urban area.Online $\mathbf{J}$ Health Allied Scs. 2010;9(2):3.

15. Bashar A, Aggarwal AK, Pilania M. A study to assess pattern of morbidities 
among adolescents under school health program from a rural block of north india. National J community Med.2017;8 (12):721-5.

16. Modi PM, Pathak S, Patel S, Srivastava R, Thomas $\mathrm{R}$ et al. Nutritional status and common morbidities among school-going adolescents of rural areas of Vadodara, Gujarat: a cross sectional study.Int J Contemp Pediatr. 2019 May;6(3):11431148.

17. Agarwal DK, Agarwal KN, Upadhyay SK, Mittal R, Prakash R et al: Physical and sexual growth pattern of children from 518 years of age: Indian Paediatr 1992 Oct;29(10):1203-1282.

18. Kaul K.K, Mukherji B, Sundaram KR, Goel RK: Growth at adolescence. 11.A study of development of secondary sex character in urban boys:Indian Paediatr .1983 Apr;20(4):249-53. 